\title{
Confecção da coleção de invertebrados e a conservação ambiental
}

\author{
Mendonça G. C. ${ }^{1 *}$; Caus R. A. ${ }^{1}$, Tavares M. T. ${ }^{1,2}$, Dall'Orto R. C. ${ }^{1,2}$, Bolzan M. S. ${ }^{3}$, \\ Rainha, K. P. 3,4 \\ 1 Departamento de Ciências Biológicas, Universidade Federal do Espírito Santo, Vitória, ES, Brasil. \\ 2 Coleção Entomológica da UFES, Universidade Federal do Espírito Santo, Vitória, ES, Brasil. \\ 3 Núcleo de Competências em Química do Petróleo (NCQP/LabPetro), Universidade Federal do Espírito Santo, Vitória, ES, Brasil \\ 4 Departamento de Teorias do Ensino e Práticas Educacionais, Universidade Federal do Espírito Santo, Vitória, ES, Brasil. \\ *e-mail: gabrielabioufes@gmail.com
}

\begin{abstract}
Resumo
Os invertebrados constituem o maior grupo de organismos vivos em riqueza e abundância. As coleções zoológicas são consideradas ferramentas didático-pedagógicas primordiais para o efetivo aprendizado de ciências. A coleção de invertebrados confeccionada tem cerca de 125 espécimes, representando os insetos, moluscos e crustáceos. A produção da coleção zoológica consiste em um valioso recurso metodológico que oportuniza a vivência de novas experiências científicas, articula os conceitos teóricopráticos e resulta na materialização dos conhecimentos.
\end{abstract}

\begin{abstract}
Invertebrates constitute the largest group of living organisms in richness and abundance. Zoological collections are considered primary didactic-pedagogical tools for the effective learning of sciences. The collection of invertebrates has around the 125 specimens, representing insects, mollusks and crustaceans. The production of the zoological collection consists of a valuable methodological resource that allows the experience of new scientific experiments, articulates the theoretical-practical concepts and results in the materialization of the knowledge.
\end{abstract}

Keywords: science teaching, zoological collection, invertebrates.

\section{Introdução}

O Brasil é conhecido pela sua "megadiversidade", estima-se que $20 \%$ das espécies conhecidas no mundo ocorram no país [1]. Ações para a manutenção, valorização e conservação dos recursos naturais são incentivadas em todo o planeta, visando preservar as formas de vida existente $[2,3]$.

Os invertebrados constituem o maior grupo de organismos vivos em riqueza e abundância. A degradação ambiental ameaça à conservação dos habitats naturais e, consequentemente, das espécies, desencadeando diversos processos que promovem 0 desequilíbrio ecológico [3,4].

Neste sentido, foi proposta a criação da coleção zoológica com a finalidade de produzir informações sobre a biodiversidade dos invertebrados e as relações estabelecidas com os seres humanos, para ser utilizado como ferramenta didático-pedagógica. $\mathrm{O}$ conhecimento materializado pelas espécies da coleção didática fomenta as discussões e reflexões sobre os fatores éticos, políticos e sociais que estão em torno do conhecimento científico e da necessidade de promover a conservação ambiental [3,5].

O objetivo desta pesquisa foi confeccionar uma coleção de invertebrados, considerando os aspectos da
Alfabetização Científica e da instrumentação para o Ensino de Ciências e de Biologia em quaisquer níveis.

\section{Metodologia}

A pesquisa qualitativa foi desenvolvida na Universidade Federal do Espírito Santo (UFES) com as contribuições do Departamento de Ciências Biológicas e de Teorias do Ensino e Práticas Educacionais, da Coleção Entomológica da UFES e do Núcleo de Competências em Química do Petróleo (NCQP/Labpetro). A Coleção Entomológica da UFES gentilmente cedeu alguns exemplares e disponibilizou sua infraestrutura, além disso seus membros ensinaram as metodologias mais adequadas de preparo. Os demais exemplares foram doados por outros pesquisadores ou comprados no mercado local. As aquisições dos materiais e espécies comercializáveis foram financiadas pelos próprios pesquisadores. Em respeito aos preceitos bioéticos, destaca-se que não foi realizada coleta e também que nenhum espécime foi morto durante a elaboração desta coleção. A equipe operacionalizou as ações para a confecção da coleção didática, em via seca e via úmida, utilizando materiais de baixo custo ou doados. A montagem em via seca foi realizada na caixa de estocagem entomológica (fabricante Papillon) feita de 
fibra de madeira (MDF) com $62 \mathrm{~cm}$ de comprimento, 47 $\mathrm{cm}$ de largura e $6,5 \mathrm{~cm}$ de altura, cuja base para alfinetação de acetato-vinilo de etileno (EVA) tinha 8 $\mathrm{mm}$ de espessura. Após a aquisição, foi confeccionada sob medida a tampa em acrílico (polimetil-metacrilato) por ser um polímero transparente, rígido, leve e altamente resistente. Para o preparo dos insetos, espetou-se o alfinete na parte superior de cada animal, posicionado na região direita do tórax e transferido para a caixa, onde cada item recebeu uma etiqueta de identificação (Figura 1). A coleção entomológica foi armazenada em local seco, contendo naftalina dentro da caixa para evitar a proliferação de alguns fungos e insetos indesejáveis. Estas condições são extremamente necessárias, no intuito de impedir danos irreversíveis aos espécimes preparados ou retardar a degradação $[2,6]$.

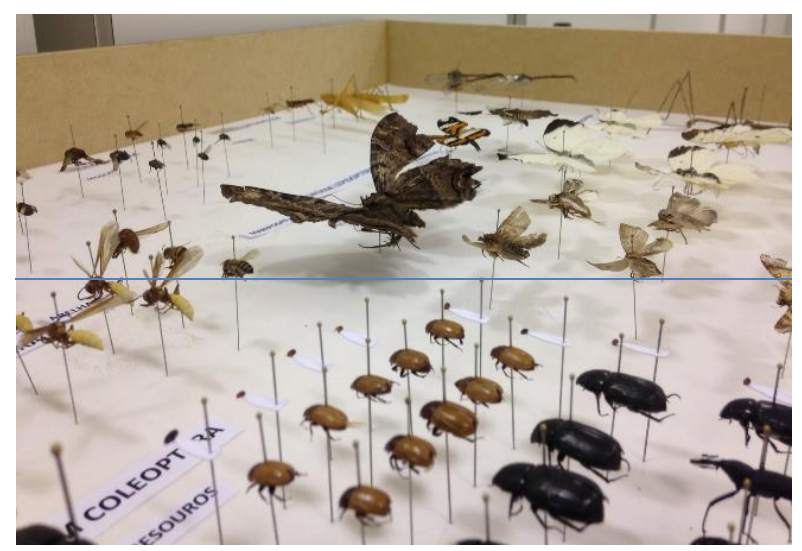

Figura 1: Processo de alfinetagem para a montagem da caixa.

Os crustáceos e moluscos foram preparados pelo processo de imersão em solução conservante, em via úmida. Inicialmente, foi realizado o procedimento de fixação em solução de formol 10\% (formaldeído ou metanal, $\mathrm{CH}_{2} \mathrm{O}$ ). Após 24 horas, os exemplares foram armazenados em potes de vidro transparente e tampa de plástico, contendo álcool $70 \%$ (álcool etílico ou etanol, $\mathrm{C}_{2} \mathrm{H}_{5} \mathrm{OH}$ ). Posteriormente, cada pote foi lacrado com plástico filme de PVC (policloreto de vinila) e recebeu uma etiqueta com a identificação do espécime $[7,8]$.

\section{Discussão dos resultados}

A coleção de invertebrados confeccionada neste trabalho registrou em torno de 125 espécimes, correspondendo aos grupos dos insetos, moluscos e crustáceos. As seguintes ordens foram representadas: Coleoptera (besouro), Decapoda (caranguejo), Diptera (mosca e mosquito), Hemiptera (percevejo e cigarra), Hymenoptera (abelha e vespa), Lepidoptera (mariposa e borboleta), Mantodea (louva-Deus), Octopoda (polvo), Odonata (libélula), Orthoptera (grilo e esperança), Phasmatodea (bicho-pau). Na caixa de estocagem foram alocados os espécimes entomológicos em via seca (Figura 2), enquanto o caranguejo e polvo foram acondicionados em via úmida nos frascos de vidro (Figura 3).

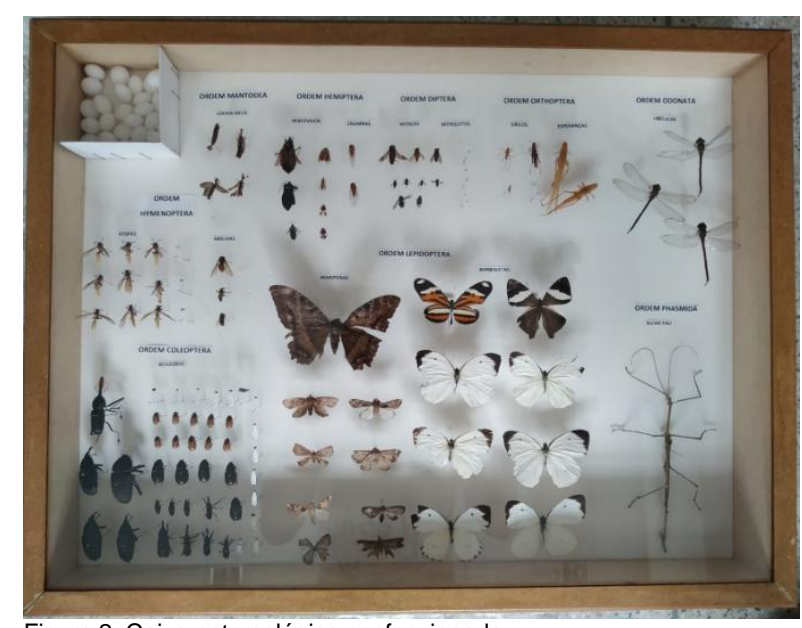

Figura 2: Caixa entomológica confeccionada.

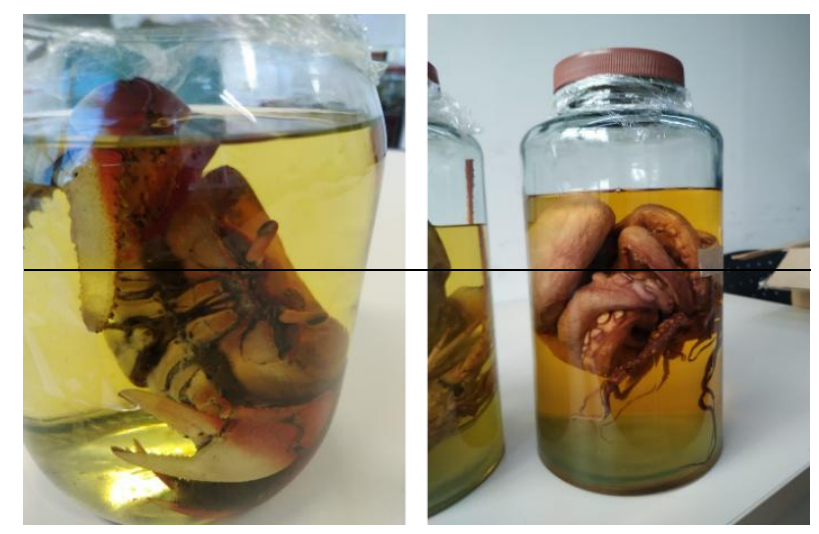

Figura 3: Caranguejo e polvo em via úmida por imersão em álcool 70\%.

Com intuito de complementar a coleção e aprimorar o processo ensino-aprendizagem, foram adquiridas casquinhas de siri, limpas e secas, que são comumente utilizadas por restaurantes locais, para exemplificar a presença de exoesqueleto nos crustáceos (Figura 4). Neste momento, é possível introduzir a discussão sobre a importância ecológica e econômica desses organismos na região. A partir desta visualização, aponta-se a existência dela em outras ordens, fazendo as informações se conectarem.

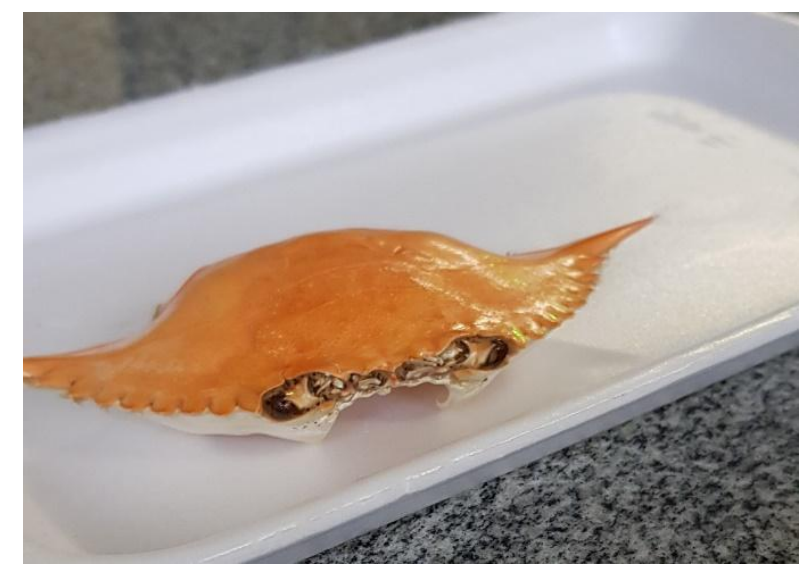

Figura 4: Casquinha de siri, exemplo de exoesqueleto. 
As coleções didáticas de zoologia são consideradas ferramentas didático-pedagógicas primordiais para 0 efetivo aprendizado no Ensino de Ciências Naturais e Biologia. A proposta metodológica para a elaboração deste produto surgiu da necessidade de fornecer elementos que aproximem o conhecimento técnicocientífico do educacional. $O$ projeto insere-se no contexto da Educação Ambiental (EA), promovendo a conscientização e a conservação ambiental [4-8].

Este tipo de material didático fornece informações sobre as características das espécies que foram tratadas, incentiva a pesquisa voluntária em função da observação e curiosidade, promove a alfabetização científica, além de possibilitar uma maior compreensão dos fatores classificatórios e das relações destes animais com o ambiente [3,7].

A confecção da coleção de invertebrados proporcionou o desenvolvimento de aspectos investigativos e criativos nos pesquisadores, em processos contínuos de ressignificação dos conceitos. A elaboração proporcionou a familiarização da equipe com as espécies sob estudo e, também, promoveu o compartilhamento de experiências e conhecimentos entre os pares. Durante os processos metodológicos foram realizadas pesquisas com a articulação teóricoprático, discussões e reflexões sobre os conteúdos e sua importância cotidiana sob a perspectiva da conservação ambiental, para além das Ciências Ambientais, objetivando produzir um suporte didático para a conscientização de uma sociedade que seja coletiva, responsável e ética $[4,5]$.

Para que a educação seja significativa, integradora e transformadora, recomenda-se o uso deste tipo de material didático-pedagógico no Ensino de Ciências e Biologia, em quaisquer níveis. Para uma próxima etapa, incentiva-se a verificação dos resultados educacionais e o desenvolvimento de diagnósticos sobre a experiência dos discentes.

\section{Conclusão}

A elaboração, aquisição e organização da coleção de invertebrados, utilizando materiais de baixo custo ou doados, favorece os processos de investigação, criatividade e ressignificação dos conteúdos conceituais. Ratifica-se a produção da coleção zoológica didática, pois consiste em um valioso recurso metodológico que oportuniza a vivência de novas experiências científicas, articula os conceitos teóricos com os práticos e resulta na materialização dos conhecimentos.

\section{Agradecimentos}

Os autores são gratos aos familiares e amigos que gentilmente se dispuseram a colaborar. Agradecem especialmente ao Departamento de Ciências Biológicas e Teorias do Ensino e Práticas Educacionais, à Coleção Entomológica da UFES e ao NCQP/LabPetro pelas contribuições, infraestrutura, recursos e apoio.
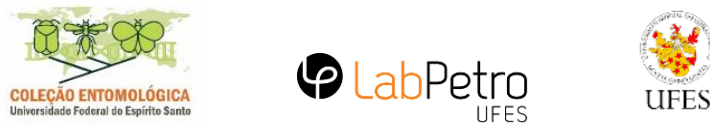

\section{Referências}

[1] O que é biodiversidade?, São Paulo. Disponível em $<$ https://www.wwf.org.br/natureza_brasileira/questoes ambientais/biodiversidade/>. Acesso em: 07 Mai. $201 \overline{9}$.

[2] SCHWANKE, C.; DORVILLÉ, L. F. M.; GAMON, M. R.; SANTANA, M. C. F.; PICHIN, J. H. G. Organização interativa de coleções didáticas em biologia. Interagir: pensando a extensão, p. 49-52, 2001.

[3] SILVA, R. L. F.; CORSO, T. M. D. Possibilidades didáticas para o ensino de zoologia na educação básica. São Paulo: Instituto de Biociências da Universidade de São Paulo: 2016.

[4] AZEVEDO, C. O.; VAZ-DE-MELLO, F. Z.; TAVARES, M. T.; BRESCOVIT, A. D.; JUNIOR, P. M.; FURIERI, K. S.; JUNIOR, K. S. B.; FREITAS, A. V. L. In: PASSAMANI, M.; MENDES, S. L. (Orgs.). Espécies da Fauna Ameaçadas de Extinção no Estado do Espírito Santo. Vitória, IPEMA - Instituto de Pesquisas da Mata Atlântica, 2007, p. 105-117.

[5] FERNANDES, S. R. S.; HOEPERS, I. S.; ALBUQUERQUE, M. H. Educação, formação profissional e sustentabilidade: articulação do ensino com a pesquisa. Em Aberto, v. 27, p. 70-89, 2014.

[6] CAMARGO, A. J. A.; OLIVEIRA, C. M.; FRIZZAS, M. R.; SONADA, K. C.; CORREAA, D. C. V. Coleções entomológicas: legislação brasileira, coleta, curadoria e taxonomia para as principais ordens. Brasília: Embrapa: 2015.

[7] PAPAVERO, N. Fundamentos práticos de taxonomia de zoológica: coleções, bibliografia, nomenclatura. São Paulo: Editora da Universidade Estadual Paulista: 1994.

[8] PEIXOTO, L. S. V. Primeira coleção didática de zoologia da Universidade Federal da Integração LatinoAmericana. 42f. Monografia de especialização. Programa de Pós-Graduação em Ensino de Ciências, Universidade Tecnológica Federal do Paraná, Medianeira, 2012.

[9] AZEVEDO, H. J. C.; FIGUEIRÓ, R.; ALVES, D. R.; VIEIRA, V.; SENNA, A. R. O uso de coleções zoológicas como ferramenta didática no ensino superior: um relato de caso. Revista Práxis, p. 43-48, 2012. 